\title{
Development of a Protective Coating for Evaluating the Sub-surface Microstructure of a Worn Material
}

\author{
U. Pranav Nayak ${ }^{1}\left[\right.$ Johannes Webel ${ }^{1} \cdot$ Valentin Pesnel $^{3} \cdot$ Frank Mücklich $^{1,2} \cdot$ María Agustina Guitar $^{1}$
}

Received: 9 September 2021 / Accepted: 2 November 2021 / Published online: 13 November 2021

(c) The Author(s) 2021

\begin{abstract}
In the current study, electrolytic deposition using two different electrodes, copper $(\mathrm{Cu})$ and nickel (Ni) was investigated with the aim of protecting the worn surface during mechanical sectioning and polishing, for a posterior examination of the sub-surface microstructure. The efficacies of the two coatings were visually assessed based on its adhesivity and the ability to protect the wear tracks of an as-cast $26 \% \mathrm{Cr}$ high chromium cast iron (HCCI) alloy. It was observed that electrodeposition using $\mathrm{Cu}$ as the electrode was ineffective owing to a poor adhesivity of the coating on the HCCI surface. The coating had peeled off at several regions across the cross-section during the mechanical sectioning. On the other hand, Ni electroplating using Ni strike as the electrolyte was successfully able to protect the wear track, and the sub-surface characteristics of the wear track could be clearly visualized. A uniform coating thickness of about $8 \mu \mathrm{m}$ was deposited after 30-40 min with the current density maintained between 1 and $5 \mathrm{~A} / \mathrm{dm}^{2}$. The presence of the $\mathrm{Ni}$ coating also acted as a protective barrier preventing the ejection of the broken carbide fragments underneath the wear track.
\end{abstract}

Keywords Surface protection - Electrolytic deposition · Nickel coating $\cdot$ Sub-surface microstructure/characterization · Unlubricated sliding $\cdot$ Particle ejection $\cdot$ High chromium cast iron

\section{Introduction}

Nearly a quarter of the world's energy produced is spent in overcoming issues related to tribology [1]. Moreover, the failures associated with friction and wear in the mining and mineral sector alone constitute for about $6 \%$ of the annual global energy consumption [2]. To mitigate the monetary and energy loss encountered during the operation, researchers are constantly seeking to understand the wear mechanisms and subsequently, improve the material in use [3, 4]. In addition to employing new materials apt for wear-related applications, existing materials can be microstructurally modified, or coated with a suitably wear resistant material

U. Pranav Nayak

pranav.nayak@uni-saarland.de

1 Department of Materials Science, Saarland University, Campus D 3.3, 66123 Saarbrücken, Germany

2 Materials Engineering Center Saarland (MECS), Campus D3.3, 66123 Saarbrücken, Germany

3 Ecole Européenne d'ingénieurs en Génie des Matériaux (EEIGM), Université de Lorraine, 54000 Nancy, France such as high chromium cast iron (HCCI) to increase their longevity [5].

HCCIs are alloys containing a dispersion of hard $\mathrm{M}_{7} \mathrm{C}_{3}$ (M: $\mathrm{Cr}, \mathrm{Fe}$ ) type carbides in a supportive, modifiable matrix (austenite, martensite, ferrite), enabling it to be used in a wide variety of applications in the mining and mineral sector, such as ball mill liners, pulverizing equipment, feeders, etc. [6-9].The versatility in the alloy's applicability in wear and/or corrosion resistant applications stems from the flexibility to vary the amount of chromium during the alloy's solidification [10-12].

A thorough characterization of the worn surface is imperative for understanding the ensuing wear mechanisms aiding in the subsequent development of better wear resistant materials. In addition to the wear-induced microstructural modifications taking place at the sample surface, examining the microstructure underneath the wear track would be beneficial for further analysis $[13,14]$. The interaction of the various phases during the wear adjacent and underneath the wear track can shed further light as the wear resistance is not an inherent property. In the specific case of HCCIs, the overall wear behaviour is a synergistic contribution between the hard carbide and the matrix that surrounds it $[3,11]$. 
As the maximum stress is experienced at the centre of the wear track $[15,16]$, it would be necessary to make a transverse cut across the entire track. Using a focused ion beam (FIB) to cut such a large section is both time and resource intensive [17]. In this regard, mechanically sectioning the sample would facilitate a complete observation of the sub-surface microstructure beneath the wear track. As the mechanical sectioning of the samples might induce certain undesired microstructural modifications, it is essential that the wear track and the underlying microstructure be suitably protected.

Electrodeposition, also known as electroplating, has long been carried out on various materials to impart certain characteristic properties [18, 19]. It involves passage of a direct current between the substrate and the metal electrode whilst they are immersed in a solution of the metal. It is one of the few surface-finishing techniques wherein the requirements of both functional and aesthetic applications can be satisfied $[20,21]$. Moreover, owing to the high degree of controllability obtainable by varying the experimental parameters, it is gaining a lot of attention from the scientific community [22, 23]. Indeed, the deposit characteristics are highly dependent on various factors such as current density, deposition time and temperature, bath composition, $\mathrm{pH}$, etc. [24, 25].

Amongst a multitude of potential electrodes, copper $(\mathrm{Cu})$ and nickel (Ni) are widely used owing to their availability and versatility in the deposition process [2, 20, 22, 26]. To prevent inaccurate analysis and erroneous interpretation, electroless Ni coating was employed in coating the oxide layers generated during the wear of a TWIP steel [13]. Moreover, edge retention during the metallographic preparation of two porous implants was also possible by electroless $\mathrm{Ni}$ coating [27]. This sheds light on the versatility of the coating methodology. Furthermore, the importance of protecting the sub-surface during mechanical sectioning can be clearly visualized in [14] where a lack of surface protection resulted in the ejection of the carbide. Therefore, it is imperative to coat the worn surface to protect the deformed sub-surface generated during the tribological testing.

The main objective of the current work was to develop a simple, yet effective approach to coat the worn surface of an HCCI sample in order to investigate the deformed microstructure underneath the wear track. Subsequently, electrodeposition was carried out using $\mathrm{Cu}$ and $\mathrm{Ni}$ as the electrodes, and their efficacies were tested. Different parameters were varied throughout the course of obtaining an optimal coating on the wear track to protect it from the ensuing mechanical sectioning and damage. Optical microscopy (OM) and scanning electron microscopy (SEM) were employed to visually assess the uniformity and adhesivity of the coatings. Additionally, EDS was used to chemically map the cross-section containing both the coating and the sub-surface. Finally, electron backscattered diffraction (EBSD) measurements were carried out to observe the deformation behaviour of the HCCI alloy underneath the wear track.

\section{Materials and Methodology}

For this work, an as-cast $26 \% \mathrm{Cr}$ HCCI alloy $(\sim \mathrm{Cr}: 26.6$ wt $\%$; C: 2.5 wt $\%$; Fe: Bal.), measuring $12 \times 15 \times 10 \mathrm{~mm}^{3}$ was subjected to dry sliding linear reciprocating tribological tests. The tests were conducted using a ball-on-disc micro-tribometer (CSM Instruments), while the whole setup was placed in an environmental chamber to control the temperature and humidity. $3 \mathrm{~mm}$ alumina $\left(\mathrm{Al}_{2} \mathrm{O}_{3}\right)$ balls (99.00-99.99\% purity; Grade GD28) was used as the sliding counter-body. The bulk chemical composition and the microstructural characterization of the HCCI alloy are given in [28], whereas the specifics of the tribological tests are described in [29]. The microstructure of the as-cast sample composed of $\mathrm{M}_{7} \mathrm{C}_{3}(\sim 30 \%)(\mathrm{M}: \mathrm{Cr}, \mathrm{Fe})$ eutectic carbides (EC) dispersed in an austenitic matrix $(\gamma)(\sim 60 \%)$, and a thin layer of martensite $\left(\alpha^{\prime}\right)(\sim 10 \%)$ sandwiched between the EC and $\gamma$.

Two electrolytic depositions with $\mathrm{Cu}$ and $\mathrm{Ni}$ as electrodes were tested. Initially, the electrodeposition with $\mathrm{Cu}$ was tested owing to the ease of availability and non-toxicity in handling the $\mathrm{Cu}$ electrolyte and later, with $\mathrm{Ni}$. A generator was used to apply of voltage of up to $1.5 \mathrm{~V}$ whereas a multimeter was used to monitor the current during the process. Figure 1 represents the schematic of the Ni electrolytic coating setup. Prior to coating, the worn sample was de-embedded from the resin and then positioned about $1 \mathrm{~cm}$ away from the electrode making sure the surfaces are parallel to each other.

Different parameters were varied throughout the course of obtaining an optimal coating on the wear track to protect it from the ensuing mechanical sectioning and damage. Tables 1 and 2 represent the various coating parameter variations employed with $\mathrm{Cu}$ and $\mathrm{Ni}$, respectively. During both the electrodeposition processes, a voltage of $1.5 \mathrm{~V}$ and a current density $(\mathrm{J})$ between 1 and $5 \mathrm{~A} / \mathrm{dm}^{2}$ was maintained.

For the Ni electro-deposition, a Ni strike electrolyte (hydrochloric acid, nickel dichloride) from Schlötter $\mathrm{GmbH}$ was used. It is important to note that the Ni strike electrolyte is highly toxic and hence, proper protective gear and precautionary measures have to be considered.

The coated samples were then mechanically sectioned to obtain the transverse section which contains the sub-surface region underneath the wear track. An abrasive disk (Struers $50 \mathrm{~A} 20$ ) rotating at $2500 \mathrm{rpm}$, with a feed rate of $0.03 \mathrm{~mm} / \mathrm{s}$ was used to obtain the cross-section of the coated samples. The transverse section was embedded in a conductive resin (WEM REM, Cloeren Technology GmbH, Germany) and metallographically prepared following the instructions 


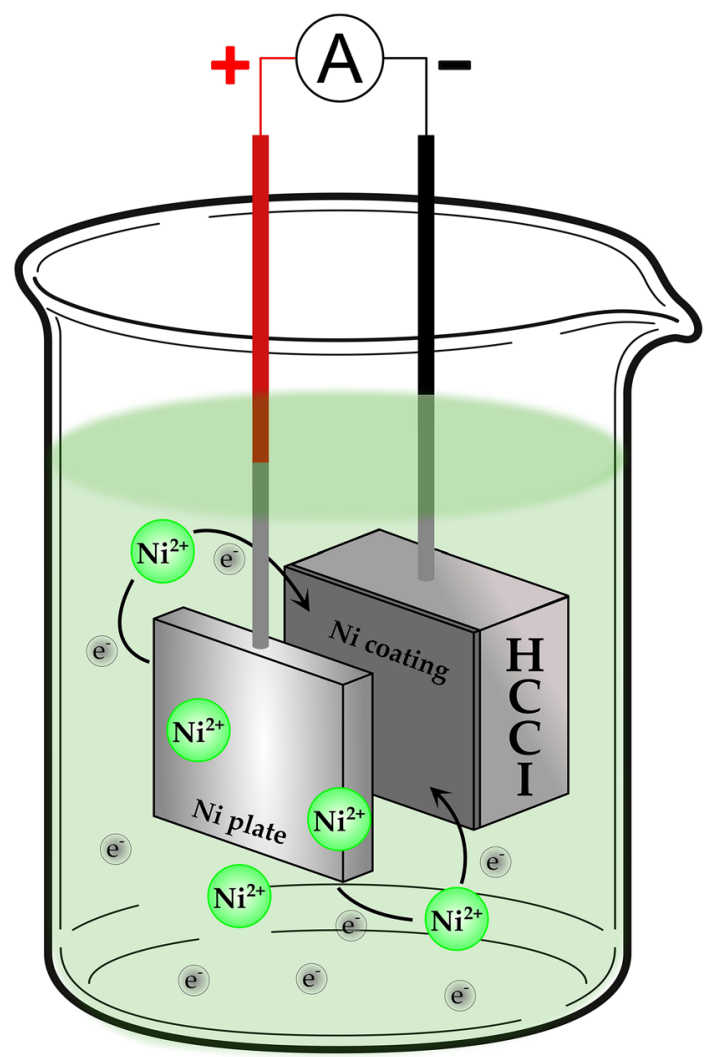

Fig. 1 Schematic of the nickel electrodeposition process

Table $1 \mathrm{Cu}$ electrodeposition parameters

\begin{tabular}{lll}
\hline Coating & Electrolyte & Time (min) \\
\hline $\mathrm{Cu} \# 1$ & $120 \mathrm{~mL} \mathrm{H}_{2} \mathrm{O}, 24 \mathrm{~g} \mathrm{CuSO}_{4} \cdot 5 \mathrm{H}_{2} \mathrm{O}$ & 10 \\
$\mathrm{Cu} \# 2$ & $120 \mathrm{~mL} \mathrm{H} \mathrm{H}_{2} \mathrm{O}, 24 \mathrm{~g} \mathrm{CuSO}_{4} \cdot 5 \mathrm{H}_{2} \mathrm{O}$ & 20 \\
$\mathrm{Cu} \# 3$ & $3 \mathrm{~min}$ gold sputtering on worn surface $+\mathrm{Cu} \# \mathbf{1}$ \\
$\mathrm{Cu} \# 4$ & $240 \mathrm{~g} / \mathrm{L} \mathrm{H}_{2} \mathrm{SO}_{4}, 110 \mathrm{~g} / \mathrm{L} \mathrm{CuSO}_{4} \cdot 5 \mathrm{H}_{2} \mathrm{O}, \mathrm{H}_{2} \mathrm{O}$ & 5 \\
$\mathrm{Cu} \# 5$ & $240 \mathrm{~g} / \mathrm{L} \mathrm{H}_{2} \mathrm{SO}_{4}, 110 \mathrm{~g} / \mathrm{L} \mathrm{CuSO}_{4} \cdot 5 \mathrm{H}_{2} \mathrm{O}, \mathrm{H}_{2} \mathrm{O}$ & 10 \\
$\mathrm{Cu} \# 6$ & 3 min gold sputtering on worn surface $+\mathrm{Cu} \# 4$ &
\end{tabular}

$\mathrm{Cu} \# 1$ and $\mathrm{Cu} \# 4$ represents the specifics of the electrolyte used as can be seen in the first row and fourth row, are given in bold

Table 2 Ni electrodeposition parameters

\begin{tabular}{llc}
\hline Coating & Electrolyte & Time $(\mathrm{min})$ \\
\hline $\mathrm{Ni} \# 1$ & Nickel strike $(\mathrm{HCl}+\mathrm{NiCl} 2)$ & 3 \\
$\mathrm{Ni} \mathrm{\# 2}$ & & 40 \\
$\mathrm{Ni} \# 3$ & & 30 \\
\hline
\end{tabular}

presented in [30] to obtain a scratch-free, mirror polished surface.

The quality of the coatings was assessed using a Leica CTR6000 optical microscope (Leica Camera AG, Wetzlar,
Germany) coupled with a Jenoptik CCD camera (Jenoptik AG, Jena, Germany), and FEI Helios Nanolab 600 field emission scanning electron microscope (FE-SEM; ThermoFisher Inc., Waltham, MA, USA, formerly FEI Company, Hillsboro, OR, USA). The SEM was operated at an acceleration voltage of 5-15 kV and a beam current of $1.4 \mathrm{nA}$. Moreover, a high sensitivity backscattered electron detector ( $\mathrm{vCD}$ ) was used to obtain a better contrast between the phases. Finally, energy-dispersive X-ray spectroscopy (EDS) was used to chemically map the crosssection containing both the coating and the sub-surface.

The local deformation and the strain distribution within the austenitic matrix underneath the wear track was investigated by electron backscatter diffraction (EBSD). The measurements were performed at an acceleration voltage of $20 \mathrm{kV}$ and a beam current of $11 \mathrm{nA}$, using a field emission gun in the FE-SEM workstation equipped with an EDAX Hikari EBSD camera (EDAX Corporation, Mahwah, NJ, USA). Additionally, misorientation profile analysis was performed within the austenitic region to obtain the orientational variation, with increasing crosssectional depth. The EBSD data was analysed using the Orientation Imaging Microscopy (OIM ${ }^{\mathrm{TM}}$ v. 7) Data Analysis software by EDAX Corporation.

\section{Results and Discussion}

The passage of an electric current between two electrodes immersed in an electrolyte is the essentiality of electrodeposition. During the electrolytic process, metal atoms lose electrons at the anode (oxidation) and get deposited at the cathode (reduction). The electrolyte contains ions, which migrate towards the electrodes with the opposite charge (positively charged ions to the cathode and negatively charged ions to the anode). The ion mobility results in the generation of a current flow, owing to the transfer of electrons, thus completing the electrical circuit [24, 26, 31]. Equations 1 and 2 represent the general half-cell reactions that take place at the anode and the cathode, respectively, where $\mathrm{M}$ is the metal atom, $\mathrm{M}^{\mathrm{n}+}$ is the metal ion, $\mathrm{n}$ is the valency, and $\mathrm{e}^{-}$is the electron charge.

$$
\begin{aligned}
& \mathrm{M} \rightarrow \mathrm{M}^{\mathrm{n}+}+\mathrm{ne}^{-} \\
& \mathrm{M}^{\mathrm{n}+}+\mathrm{ne}^{-} \rightarrow \mathrm{M}
\end{aligned}
$$

The properties and structures of the electrodeposits are closely related to the electrolyte composition and electroplating parameters [26, 32]. In the current study, only the type of electrode $(\mathrm{Cu} / \mathrm{Ni})$, electrolyte, and time was varied to reduce the degrees of freedom. 


\subsection{Copper Electrodeposition}

Figure 2 represents the optical micrograph $(\mathrm{OM})$ of the samples' sub-surface after $\mathrm{Cu}$ electrodeposition using recipe \#4 (Table 1). The bright field (BF) (Fig. 2a) mode of the optical microscope was used in conjunction with the differential interference contrast (DIC) mode (Fig. 2b) to reveal the various characteristics of the sub-surface and the $\mathrm{Cu}$ coating. The different phases present in the HCCI sample is indicated in Fig. 2a, whereas the inherent topography present between the EC and the matrix was visualized using the DIC mode, indicated in Fig. 2b [33, 34]. From Fig. 2b, a lack of adhesion of the $\mathrm{Cu}$ coating with the HCCI substrate was observed. Consequently, the coating was peeled off at several regions across the cross-section during the mechanical sectioning. The dashed yellow ellipse in Fig. 2a is indicative of one such incidence. Despite a lack of adhesivity, the coating thickness was fairly uniform across the surface, and it was measured to be $6.5 \pm 0.3 \mu \mathrm{m}$.

During the electrodeposition process, oxidation of $\mathrm{Cu}$ takes place at the anode resulting in the generation of copper ions $\left(\mathrm{Cu}^{2+}\right)$ and free electrons $\left(\mathrm{e}^{-}\right)$. The copper salt $\left(\mathrm{CuSO}_{4} \cdot 6 \mathrm{H}_{2} \mathrm{O}\right)$ present in the electrolyte dissociates into the respective copper and sulphate ions $\left(\mathrm{SO}_{4}{ }^{2-}\right)$. When the potential is applied, the mobile copper ions combine with the free electrons to form metallic copper at the cathode (HCCI substrate). In addition to the generation of copper ions, the dissociation of water also generates hydrogen ions
$\left(\mathrm{H}^{+}\right)$ions. As the cationic activity of $\mathrm{Cu}^{2+}$ ions are higher than $\mathrm{H}^{+}$ions, its tendency to gain electrons is higher and hence, $\mathrm{Cu}$ is formed at the cathode [24, 25]. Similarly, the anionic activity of $\mathrm{OH}^{-}$is higher than $\mathrm{SO}_{4}{ }^{2-}$ and therefore, loses its electron more readily. Finally, the $\mathrm{H}^{+}$ion combines with the $\mathrm{SO}_{4}{ }^{2-}$ ion to form $\mathrm{H}_{2} \mathrm{SO}_{4}$, a colourless liquid.

The lack of adhesion could be attributed to: (i) the sulphate bath's acidity combined with the high activity of $\mathrm{Cu}$ resulting in the formation of a non-adherent immersion deposit upon solution contact [24] and/or (ii) the presence of an inherent passive oxide film on the HCCI substrate and the inability of the sulphate-based electrolyte to destroy it. The passive oxide layer could hinder the formation of a mechanically stable copper/oxide interface. The HCCI family of alloys owe their superior wear and corrosion resistance to the presence of chromium, which contributes to the formation of hard chromium-based carbides within the microstructure, and an impervious oxide film on the surface [6, 7]. This allows them to be used in applications in the mining and mineral industries, where both dry and/or wet corrosive environments are encountered [8, 11,35]. Additionally, it was reported in [36] that a chromium content of above 16 wt $\%$ will generate an oxide layer of the type $\mathrm{FeO} \cdot \mathrm{Cr}_{2} \mathrm{O}_{3}$. In the current alloy, the bulk $\mathrm{Cr}$ composition is about $26 \mathrm{wt} \%$ which is distributed between the EC and the matrix. It is worth to note that the formation of the oxide film is dependent on the chromium content present in the matrix alone [7, 36]. In a previous study [28], the chromium content of the
Fig. 2 OM of the cross-section of the sample surface after $\mathrm{Cu}$ \#4 electrodeposition where: a $\mathrm{BF}$ micrograph indicating the various phases within the $\mathrm{HCCI}$ microstructure as well as the $\mathrm{Cu}$ coating. A non-uniformity in the coating is represented by the dashed yellow ellipse and $\mathbf{b}$ DIC micrograph wherein the dashed yellow rectangle indicates a lack of adhesion of the $\mathrm{Cu}$ coating with the HCCI substrate (Color figure online)
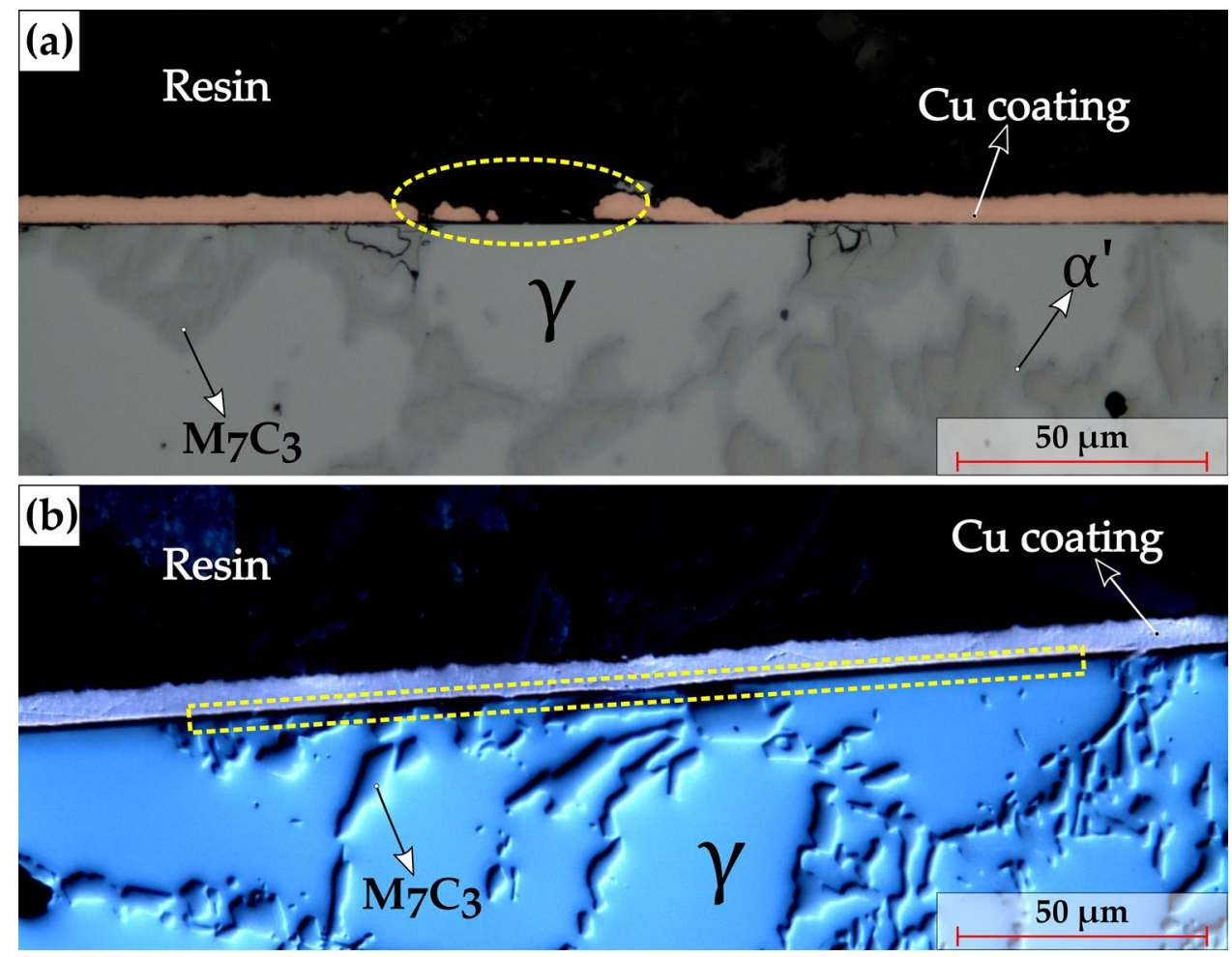
matrix was calculated using electron probe micro analysis (EPMA) and MatCalc simulations, and it was found to be around $\sim 18 \mathrm{wt} \%$. Hence, in the current alloy, an oxide film consisting of a complex mixture of iron and chromium can be expected. Although an iron-based oxide film could be removed by immersion into sulphuric acid, the chromiumbased oxide is impervious to it [31].

It must be noted that in all the cases, the $\mathrm{Cu}$ coatings were extremely fragile and not adherent on the HCCI sample substrate. The lack of adhesion of direct $\mathrm{Cu}$ on steel substrates was also seen in other studies [37]. $\mathrm{Cu} \# 4$ coatings were relatively better compared to the rest which could be attributed to the presence of sulphuric acid and the increased concentration of the $\mathrm{CuSO}_{4}$ salt. The sulphuric acid ensures an increase in conductivity and a corresponding decrease in the anode and cathode polarization, preventing the precipitation of basic $\mathrm{Cu}$ salts [26]. Nevertheless, the inability of the coating to protect the wear surface as observed from Fig. 2,

Table 3 Remarks on the coating characteristics for the $\mathrm{Cu}$ electrodeposited samples with varying parameters

\begin{tabular}{lc}
\hline Coating & Remark \\
\hline $\mathrm{Cu} \# 1$ & No adhesion. Fragile coating \\
$\mathrm{Cu} \mathrm{\# 2}$ & No adhesion. Fragile coating \\
$\mathrm{Cu} \mathrm{\# 3}$ & No adhesion. Fragile coating \\
$\mathrm{Cu} \mathrm{\# 4}$ & Sporadic adhesion. Better \\
& results than \#1, \#2 and \#3 \\
$\mathrm{Cu} \mathrm{\# 5}$ & Sample corroded due to \\
& sudden voltage increase \\
$\mathrm{Cu} \# 6$ & to $18 \mathrm{~V}$ \\
\hline
\end{tabular}

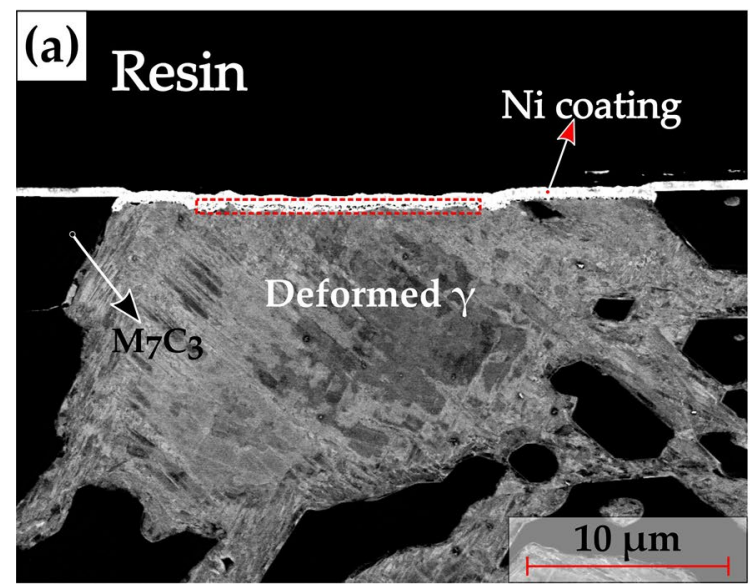

Fig. 3 Representative BSE micrograph of the sub-surface after a 3-min Ni electrodeposition with a low magnification image showing the Ni coating along with the characteristics of the sub-surface after the tribological test, $\mathbf{b}, \mathbf{c}$ showing the sporadicity in the adhesion of renders it ineffective. Table 3 sums up the remark for each case with the final observations.

Alternatively, it is reported that usage of an alkaline or a cyanide-based bath would aid in the initial deposition of a thin $(<2.5 \mu \mathrm{m})$ adherent layer on the surface of active metal (iron, in our case). Further increase in the deposit thickness can be facilitated using an acid sulphate bath [24, 38]. Nonetheless, considering the toxicity and the health hazards associated with cyanide and its handling, it was decided to proceed with Ni electrodeposition.

\subsection{Nickel Electrodeposition}

In the present study, a pure Ni plate was used as the anode and the electrolyte was a Ni strike solution. The Ni strike contains soluble nickel salts $\left(\mathrm{NiCl}_{2} \cdot 6 \mathrm{H}_{2} \mathrm{O}\right)$ along with other constituents $(\mathrm{HCl}+$ additives). The dissolution of the salts produces positively charged, divalent nickel ions $\left(\mathrm{Ni}^{2+}\right)$ and upon the application of an electric potential, the positive ions react with the free electrons $\left(\mathrm{e}^{-}\right)$to convert to metallic $\mathrm{Ni}$ at the cathode surface (HCCI substrate), as schematically shown in Fig. 1.

\subsubsection{Ni Electrodeposition: $3 \mathrm{~min}$}

Figure 3 represents the SEM backscattered electron (BSE) micrographs of the sub-surface after a 3-min Ni electrolytic deposition. The deformed austenitic matrix under the worn surface is clearly visible and the Ni coating is uniform across the surface with a measured thickness of $0.7 \pm 0.1 \mu \mathrm{m}$. Despite the uniformity in the coating thickness, the adhesiveness is sporadic as visualized by comparing Fig. $3 b$ and c. Moreover, the dashed red enclosures in

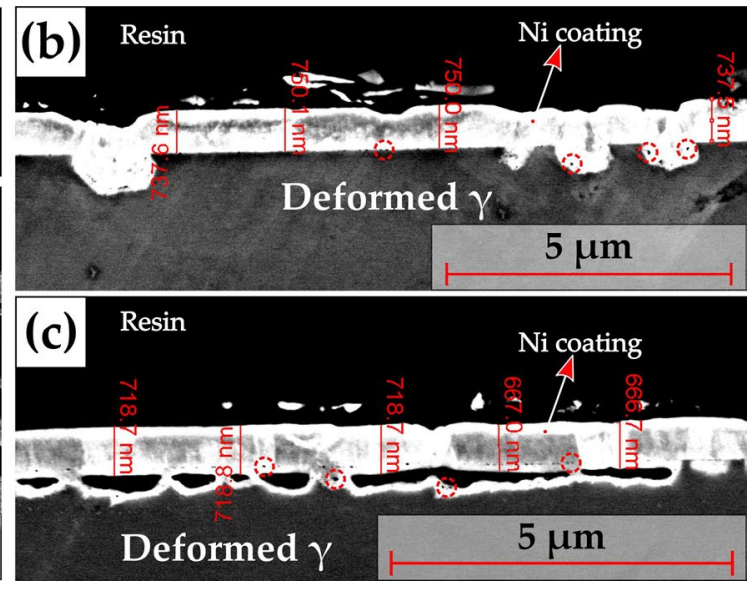

the Ni coating. The coating is fairly uniform with a thickness of about $0.7 \mu \mathrm{m}$. The dashed red circles indicate the presence of a black pits which could be a consequence of hydrogen evolution during the electrolytic process (Color figure online) 
Fig. 3 indicate the presence of black pits inside the coating which could be a consequence of hydrogen evolution at the cathode $[25,39,40]$. In the case of Ni electroplating, hydrogen co-deposition is practically unavoidable as $\mathrm{Ni}$ ions are thermodynamically more stable in aqueous solutions than hydrogen ions. Therefore, the reduction of hydrogen to hydrogen gas is thermodynamically more favourable and will occur simultaneously in conjunction with the reduction of Ni ions [41, 42]. As the present electrolyte used is acidic in nature, hydrogen ion reduction $\left(2 \mathrm{H}^{+}+2 \mathrm{e}^{-} \rightarrow \mathrm{H}_{2} \uparrow\right)$ preferentially occurs compared to the reduction of water molecules $\left(2 \mathrm{H}_{2} \mathrm{O}+2 \mathrm{e}^{-} \rightarrow \mathrm{H}_{2} \uparrow+2 \mathrm{OH}^{-}\right)[23,31]$. Moreover, considering that the experiment was carried out in air, the aqueous solution will facilitate in the reduction of oxygen too $\left(\mathrm{O}_{2}+4 \mathrm{H}^{+}+4 \mathrm{e}^{-} \rightarrow 2 \mathrm{H}_{2} \mathrm{O}\right)$. All of these reactions result in a decrease in the cathodic current efficiency (CCE). As the CCE is less than $100 \%$, there is a tendency for the $\mathrm{pH}$ to increase temporally as the $\mathrm{H}^{+}$ions are discharged to liberate hydrogen gas $\left(\mathrm{H}_{2}\right)$.

The co-deposition of hydrogen in the metallic substrate occurs initially as $\mathrm{H}$ atoms and not as $\mathrm{H}_{2}$ molecules. The reduced hydrogen ions can seep in through the broken passive oxide layer, facilitating hydrogen absorption and with time, they may congregate in vacancies or voids leading to hydrogen embrittlement [20]. The hydrogen bubbles evolved at the vicinity of the cathode cling to the freshly electrodeposited surface in an adsorbed state $\left(\mathrm{H}_{\mathrm{ads}}\right)$, resulting in the development of gas pores in the deposit [39]. Consequently, they could act as an obstacle for subsequent deposition, resulting in the formation of black pits as seen in Fig. 3 [38]. Moreover, the presence of additives in the electrolyte could also contribute to the formation of gas pores due to their ability to modify the surface tension. The proton electronation and the hydrogen evolution at the cathode can be broken down as the following [31,39-41]:

$\mathrm{H}^{+}+\mathrm{e}^{-} \rightarrow \mathrm{H}_{\mathrm{ads}}$

$\mathrm{H}_{\mathrm{ads}}+\mathrm{H}^{+}+\mathrm{e}^{-} \rightarrow \mathrm{H}_{2}$

$2 \mathrm{H}_{\mathrm{ads}} \rightarrow \mathrm{H}_{2} \uparrow$

Despite the presence of hydrogen and its impact during the $\mathrm{Ni}$ electrodeposition, the improved adhesivity of the $\mathrm{Ni}$ coating compared to its $\mathrm{Cu}$ counterpart could stem from the breakage of the passive oxide film by the chloride ions $\left(\mathrm{Cl}^{-}\right)$, which is elucidated further.

\subsubsection{Ni Electrodeposition: $40 \mathrm{~min}$}

3.2.2.1 Unworn Surface Figure 4a represents the SEM BSE micrograph of the transverse section of the HCCI surface, away from the wear track after a 40-min Ni electrodeposi- tion. The various phases present within the HCCI microstructure along with the $\mathrm{Ni}$ coating is marked for reference. Figure $4 \mathrm{~b}$ represents a magnified image of the dashed orange enclosure indicated in Fig. 4a, where the EDS measurements were carried out. Three EDS select area scans, focusing on the $\mathrm{Ni}$ coating (Area 1), the austenitic matrix (Area 2), and the EC (Area 3), in addition to two EDS line scans (A and B) were performed as delineated in Fig. 4b. The resulting EDS spectra along with the semi-quantitative phase analysis for the three corresponding areas $(1,2$, and 3$)$ is represented in Fig. 4c-e. Finally, the results of the EDS line scans with $\mathrm{A}$ and $\mathrm{B}$ as the starting points is graphically represented in Fig. $4 \mathrm{f}$ and $\mathrm{g}$, respectively.

Visual observations from Fig. $4 \mathrm{a}$ and $\mathrm{b}$ indicate that the $\mathrm{Ni}$ coating was uniform and adherent across the substrate, with a measured thickness of $8.0 \mu \mathrm{m} \pm 0.9 \mu \mathrm{m}$. Comparing Figs. 3 and 4b, the amount of pitting has significantly decreased and intuitively, the coating thickness has increased about ten-fold. Moreover, the sporadicity of adhesion as seen in Fig. 3 is not observed here, as enough time was given for the coating to adhere and grow.

The improved adhesivity can be attributed to the ability of the chloride ions $\left(\mathrm{Cl}^{-}\right)$to breakdown the tenacious chromium oxide-based passive film (unlike the $\mathrm{SO}_{4}{ }^{2-}$ ), inherently present on the HCCI surface [36, 43-47]. This results in the exposure of a fresh, oxide-free surface towards the $\mathrm{Ni}$ reduction, enabling an adherent coating during the electrodeposition. As the electrolyte used in the current electrodeposition consists of a chloride-based nickel salt $\left(\mathrm{NiCl}_{2} \cdot 6 \mathrm{H}_{2} \mathrm{O}\right)$, the chloride ions present in the bath displaces the water molecules and forms various complexes increasing the bath's acidity, thereby damaging the complex chromium-iron oxide layer. The temporal increase in the bath's acidity (decrease in the $\mathrm{pH}$ ) has a dual effect, of lowering the film breakdown potential (making it easier for film rupture) and increasing the substrate passivation potential (making it difficult for repassivation) [19, 31]. Granted that re-passivation can take place, the presence of $\mathrm{HCl}$ prevents it [48]. Moreover, the removal of the passive layer may trigger a localized corrosion of the underlying metallic surface, but the presence of the $\mathrm{M}_{7} \mathrm{C}_{3}$ chromium carbides (EC) in combination with the chromium and molybdenum in the matrix can greatly inhibit this $[7,12,49]$.

Depending on whether the select area scan falls inside the coating (Fig. 4c), matrix (Fig. 4d) or the carbide (Fig. 4e), the corresponding EDS spectra evidenced an abundance in nickel, iron and chromium, respectively. The EDS line scans in Fig. $4 \mathrm{f}$ and $\mathrm{g}$ depicts a decrease in the $\mathrm{Ni}$ intensity while crossing over from the coating to the substrate. Comparing the line scans, a sharper drop in $\mathrm{Ni}$ is seen when the carbide is present at the interface. Whenever a matrix or the carbide is encountered, a corresponding increase in iron or chromium is observed. Nevertheless, the integrity of the 

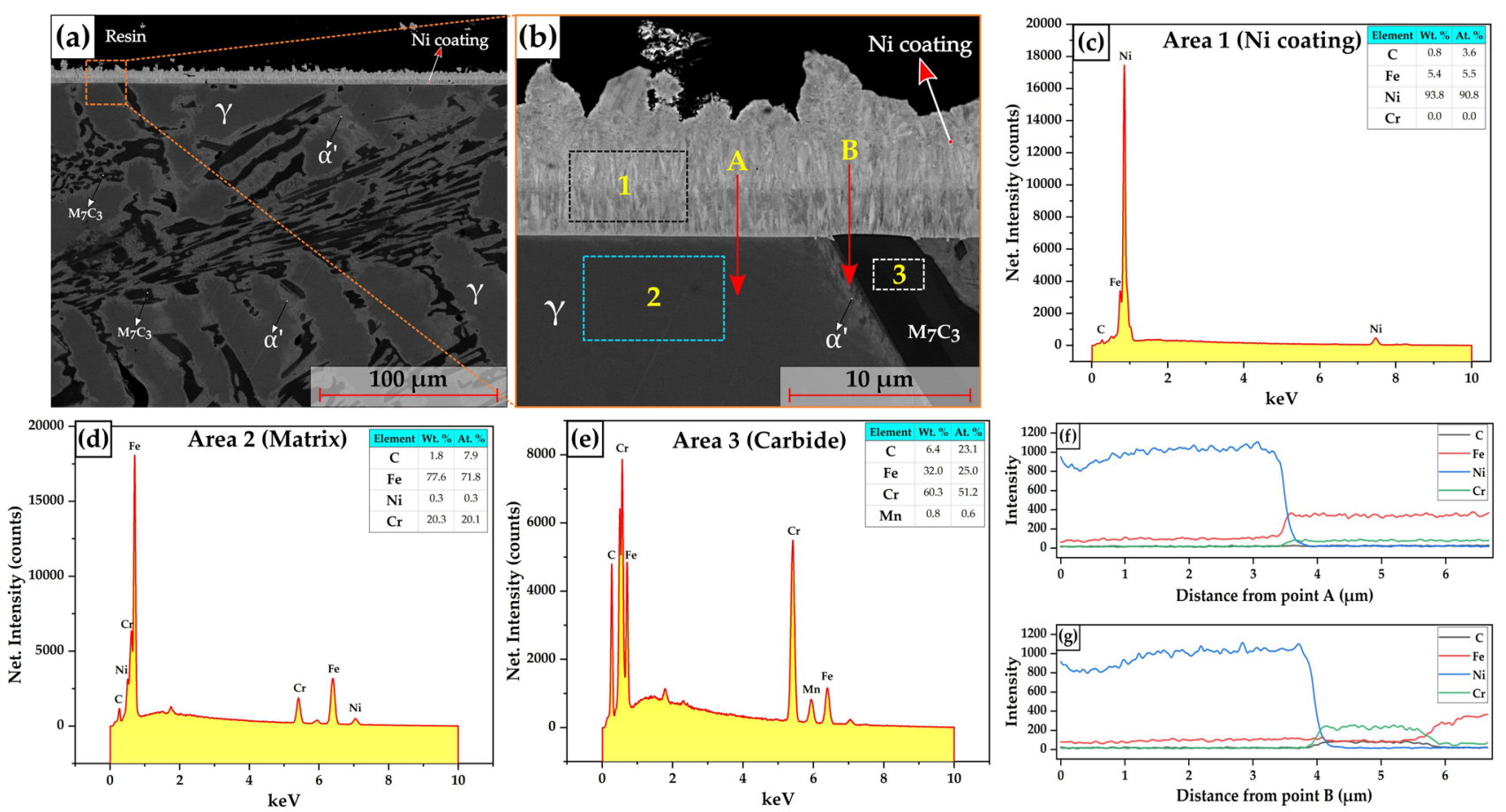

Fig. 4 a BSE micrograph of the sub-surface away from the wear track with the various HCCI phases and the Ni coating labelled for reference; $\mathbf{b}$ represents the magnified image of the dashed orange square marked in a where the EDS select area scans and line scans were performed; $\mathbf{c}-\mathbf{e}$ represent the resulting EDS select scan spectrum with the semi-quantitative analysis of the phases indicated in the respective graphs and finally, $\mathbf{f}, \mathbf{g}$ represent the results of the EDS line scan performed with A and B [marked in (b)] as the starting point (Color figure online)

ite. Further characterization and elaboration concerning the deformation behaviour of the alloy under dry sliding can be found in [29]. Comparing the coating on either side of the wear track edge, no significant differences in the thickness and adhesivity of the coating is visible, indicating uniformity. The coating was able to cover the worn surface completely despite the presence of a topography and a higher roughness compared to the unworn region. The existence of a distinct deformed and undeformed austenite across the entire sub-surface indicates that the metallographic preparation of the transverse section did not induce any additional deformation. Consequently, it can be stated that the austenitic deformation is solely due to the tribological testing.

Figure 6a represents the SEM BSE micrograph of the sub-surface directly under the wear track with the various constituents delineated. A magnified image of the dashed yellow and orange enclosures marked in Fig. 6a, is presented in Fig. $6 \mathrm{~b}$ and c, respectively. From Fig. 6b, small black pits (marked with the dashed red enclosure) were observed at the contact interface which could be attributed to the hydrogen adsorption $\left(\mathrm{H}_{\mathrm{ads}}\right)$ during the electrodeposition process, as elucidated before. The location and morphology of the pits suggest they could be bridged pores, as nomenclated by Dini [38]. Even though the efficiency of the Ni deposition is 
Fig. 5 a SEM BSE micrographs of the transverse section encompassing both the worn and the unworn regions. The dashed orange vertical line represents the wear track edge. The respective HCCI microstructural phases are marked for reference along with the Ni coating. The dashed red enclosure represents the tribologically transformed zone (TTZ); b Magnified BSE micrograph of the worn area as indicated in (a). The Ni coating is marked for reference and the dashed enclosure indicates the TTZ (Color figure online)
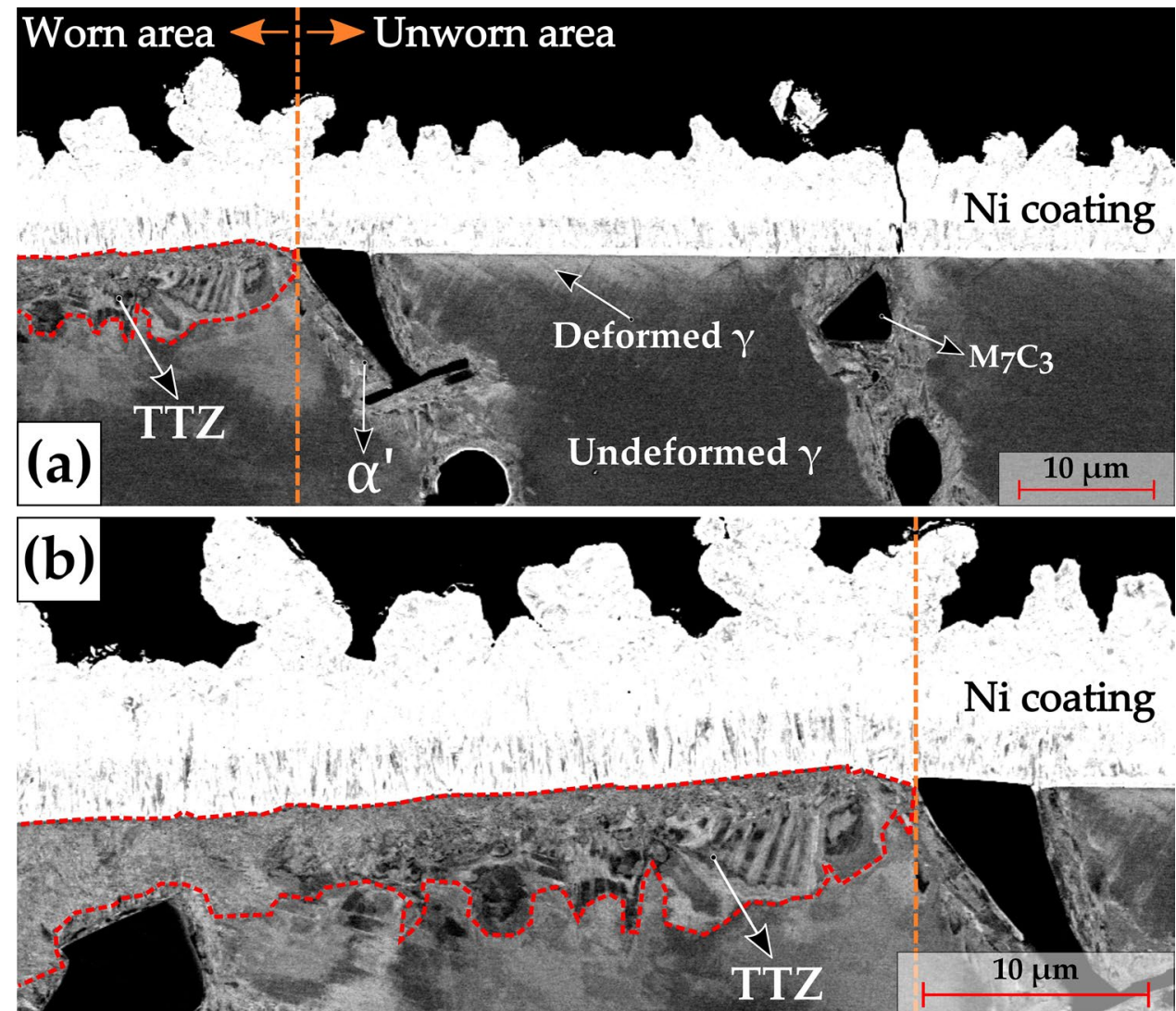

affected by $\mathrm{H}_{\mathrm{ads}}$, its presence did not hinder the formation of a compact metallic deposit [40], and the subsequent protection of the material's sub-surface.

In addition to the plastic deformation undergone by the austenite during the tribological testing, the EC had also succumbed to micro-cracking, as indicated within the dashed orange ellipse Fig. 6c. This behaviour of the EC during the tribological testing can have an influence on the overall wear behaviour of the alloy $[51,52]$. Interestingly, it is observed that the Ni coating had infiltrated these crevices and acted as an anchor to prevent the carbide's ejection during the mechanical sectioning, post-wear. This can be clearly visualized in Fig. 6c and also from the nickel EDS map in Fig. 6d. Additionally, the elemental distributions pertaining to chromium, iron and carbon are represented in Fig. 6e-g, respectively.

Increasing the deposition time facilitated a uniform adhesive Ni coating and ultimately allowed to characterize the material volume just below the worn and unworn surface. The coating had helped in preservation of the edge where the deformed structure was visible in the as-is condition. Chemical and structural analysis was carried out to assure no changes due to the Ni electrodeposition had occurred.

Figure 7a represents the SEM SE micrograph of the region underneath the wear track and the orange dashed enclosure is indicative of the area where the EBSD measurements were performed. It is worth to note that in the current study, dry sliding wear tests were carried out at a load of $20 \mathrm{~N}$, which is higher than the critical load $\left(\mathrm{P}_{\mathrm{C}}\right)$ of the HCCI alloy under study. More information concerning the critical load calculations is given in [29]. From the image quality (IQ) map in Fig. 7b, the plastic deformation of the austenitic region can be clearly visualized, and its consequence is reflected in the inverse pole figure (IPF) maps in Fig. 7c and d. Additionally, the variance in the slip directions is marked with the red-dashed lines in the IQ map for reference. The activation of slip traces is a manifestation to accommodate the deformation endured by the austenitic matrix during the tribological test [53-55].

Owing to the identical Bravais lattice structure of austenite and $\mathrm{Ni}$, i.e., face centered cubic (FCC), it was not possible to distinguish them using the EBSD phase map. However, from the IQ (Fig. 7b) and EDS map (Fig. 6), a distinction between the two could be made. It was also observed that the Ni coating had not been subjected to deformation during the metallographic preparation of the specimen. Moreover, the identicality of the crystal structures of austenite and $\mathrm{Ni}$ could influence the coating's growth characteristics. As seen from the IPF map in Fig. 7c, the Ni coating grows in a columnar fashion, although further discussion on this aspect is out of scope 

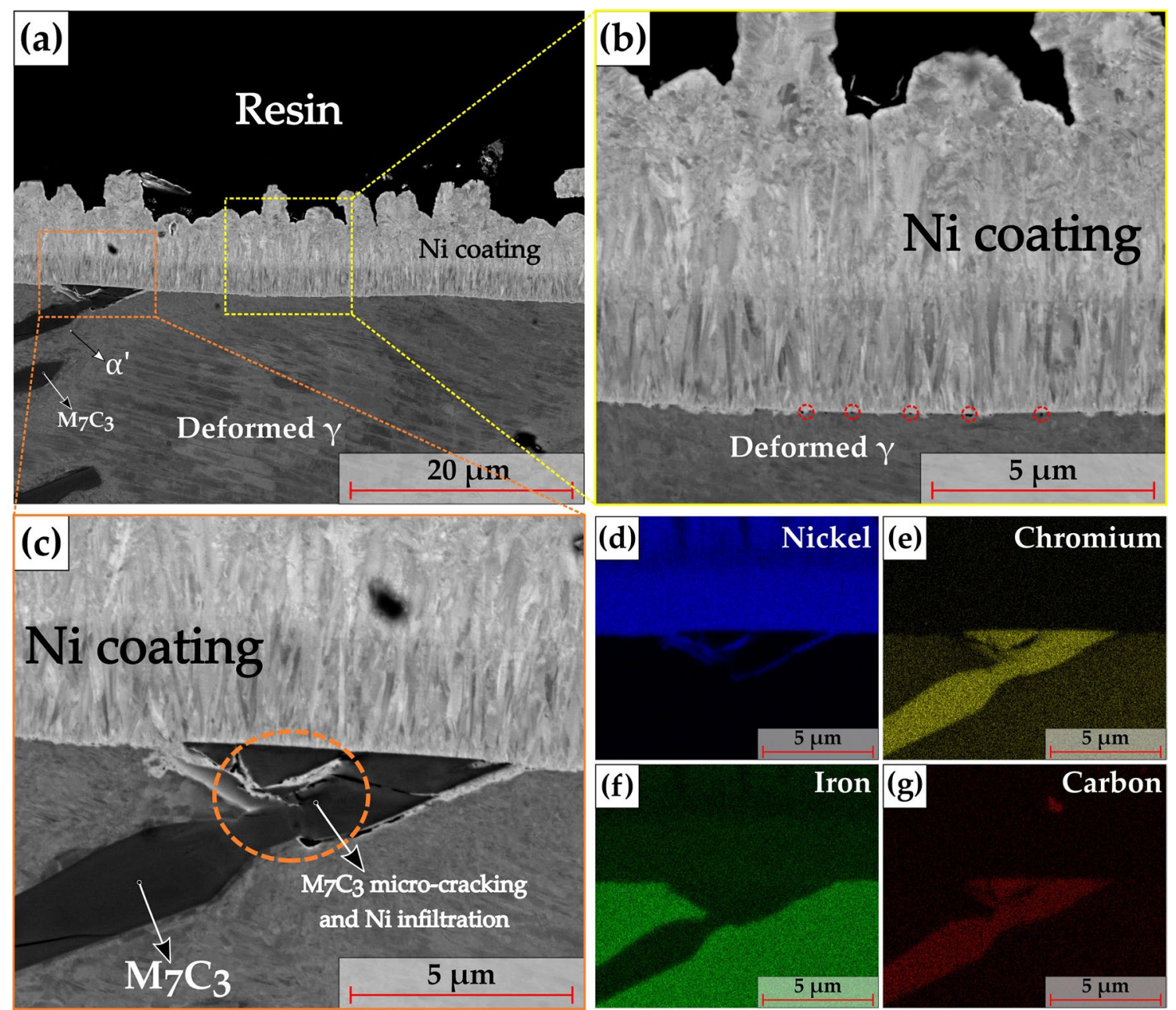

Fig. 6 a BSE micrograph of the sub-surface under the wear track with the various HCCI phases and Ni coating labelled for reference; b, $\mathbf{c}$ represent the magnified BSE micrographs of the dashed yellow and orange rectangle, respectively. The red circles in $\mathbf{b}$ indicate the formation of black pits (hydrogen pitting), an unwanted product dur-

for the present work. Nevertheless, the integrity of the coating across the entire substrate is intact.

Furthermore, the variation in the orientation across the austenite grain was elucidated by calculating the point-topoint and point-to-origin misorientation profile (MP) chart, as represented in Fig. 7e. The point $\mathrm{O}$ (as marked in Fig. 7d) was selected as the origin point, as it lies away from the immediate wear surface and the MP measurements were carried out proceeding closer towards the deformed austenite. The point-to-origin plot indicates a maximum gradient of about $12^{\circ}$ between the undeformed and deformed austenite region.

Finally, to visualize the influence of Ni electrodeposition in protecting the wear track, a piece of transparent tape was applied to half of the worn sample, effectively inhibiting the Ni coating. The Ni electrodeposition was

ing the electrolytic deposition. Carbide microcracking is visible in (c) along with the $\mathrm{Ni}$ infiltration in between the cracks. $\mathbf{d}-\mathbf{g}$ represent the EDS concentration maps of $\mathrm{Ni}, \mathrm{Cr}, \mathrm{Fe}$ and $\mathrm{C}$, respectively, of the micrograph presented in (c) (Color figure online)

carried out for 30 min by keeping the rest of the parameter's constant. Figure 8a and b represent the SEM BSE micrographs of the two opposite surfaces underneath the wear track with, and without the Ni coating, respectively.

Clearly, the presence of a uniformly coated Ni layer has protected the worn surface and prevented the chipping of the brittle EC during the sectioning. The coating thickness was measured to be $7.9 \pm 0.3 \mu \mathrm{m}$ which was similar to the $\mathrm{Ni}$ electrodeposition at $40 \mathrm{~min}$, indicating a saturation level. It was seen from Fig. 8a that the EC closer to the worn surface had cracked owing to the stress exerted on them and moreover, the Ni coating had infiltrated the cracks acting as an anchor to prevent their ejection. On the other hand, Fig. $8 \mathrm{~b}$ shows that the fragmented carbides were ejected during the mechanical sectioning process (as 
Fig. 7 a SEM SE micrograph of the region underneath the wear track, with the respective phases marked. The dashed orange rectangle in a represents the area where the EBSD measurements were carried out, with b IQ map of the scanned region, with the red-dashed lines indicating the various slip traces in the deformed austenitic matrix. c, $\mathbf{d}$ represent the IPF map overlayed with the local lattice rotation of the entire region and the single austenitic region, respectively. The variation of the misorientation angle across the austenite grain from the point $\mathrm{O}$ following a path indicated by the dashed blue line in (d), is graphically represented in (e) (Color figure online)
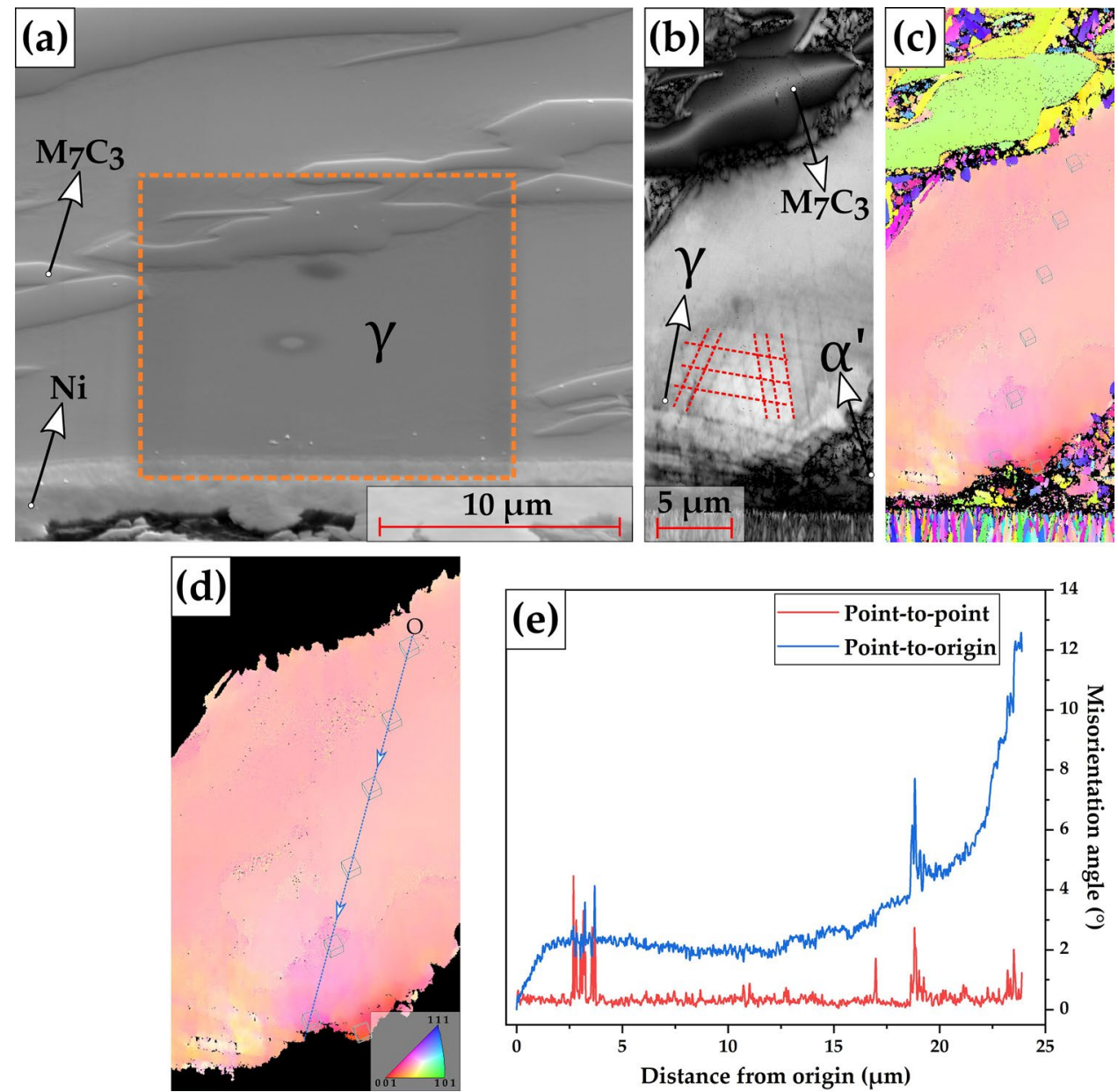

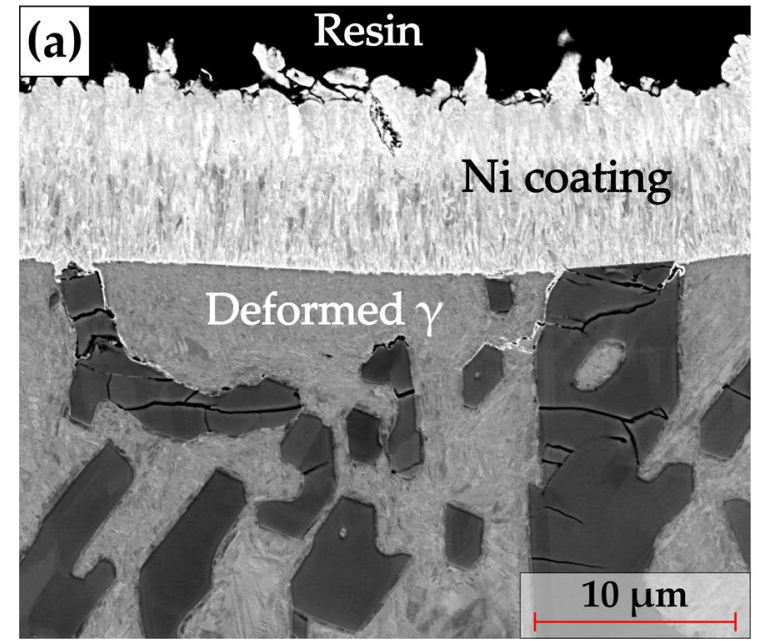

Fig. 8 Representative SEM BSE micrographs of the cross-section of the worn sample a with the electrolytic Ni deposition for $30 \mathrm{~min}$, and $\mathbf{b}$ without $\mathrm{Ni}$ electrodeposition. The dashed orange ellipse and the dashed yellow ellipse in $\mathbf{b}$ indicates the fragmentation and ejec-

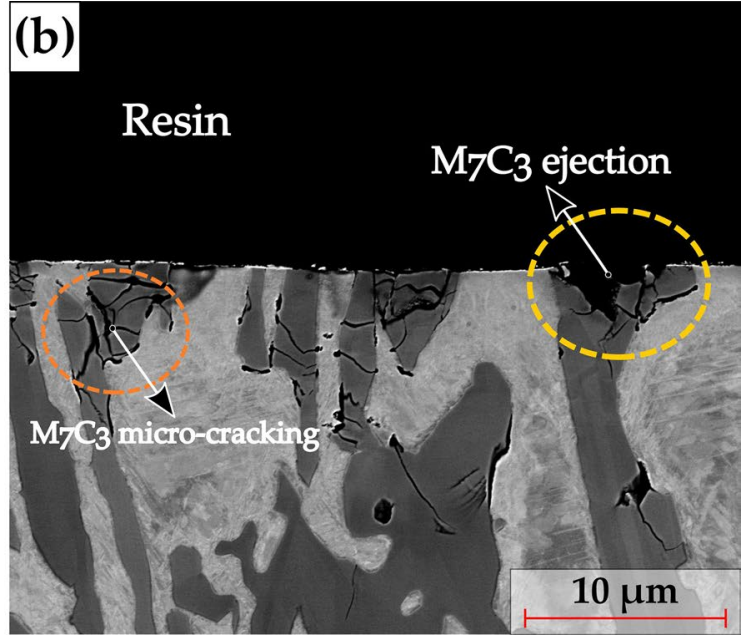

tion of the $\mathrm{M}_{7} \mathrm{C}_{3}$ carbide, respectively. It can be visualized from a that the presence of the $\mathrm{Ni}$ coating layer has protected the spalled carbides from being ejected (Color figure online) 
indicated in the dashed yellow ellipse), thus emphasizing the benefits of $\mathrm{Ni}$ electrodeposition.

\section{Conclusions}

In the current work, electrolytic deposition was carried out on the worn surface of an as-cast HCCI alloy to prevent any unwanted microstructural modifications during the mechanical sectioning and polishing, in order to examine the microstructure of the sub-surface. The efficacies of electrodeposition using $\mathrm{Cu}$ and $\mathrm{Ni}$ as the electrode were assessed by changing various experimental parameters and the following conclusions were drawn:

1. Electrodeposition using $\mathrm{Cu}$ did not yield satisfactory results as the coatings were non-uniform and poorly adhered to the substrate and were hence deemed ineffective.

2. Ni electroplating using the Ni strike electrolyte produced a uniform and adherent coating with a thickness of about $8 \mu \mathrm{m}$ after 30-40 min with the current density maintained between 1 and $5 \mathrm{~A} / \mathrm{dm}^{2}$ for the HCCI sample. Furthermore, this coating methodology was successfully applied to other ferrous alloys such as 316L stainless steel and a low-carbon steel with $5 \mathrm{wt} \% \mathrm{Ni}$. The Ni coating had helped in preserving the sample edge and the sub-surface characteristics underneath the wear track could be clearly visualized.

3. EDS maps clearly show the presence of a uniform $\mathrm{Ni}$ layer whereas the line scan across the interface shows no chemical alteration of the surface in the sub-micron range. No significant differences in the integrity of the coating were observed between a Ni-matrix and a $\mathrm{Ni}$ carbide contact.

4. The Ni infiltration into the broken carbide fragments acted as an anchor preventing its ejection during the mechanical sectioning and polishing, as evident from Figs. 6 and 8.

Acknowledgements The authors are thankful to Martin Duarte from Tubacero S.A. for providing the material. The authors would like to thank the Saarland State Chancellery for financial support within the ZuMat Project funded by the European Regional Development Fund (ERDF). Additionally, U.P.N. is grateful to DAAD for the financial support and J.W. gratefully acknowledges the financial support by CBMM (Brazil).

Funding Open Access funding enabled and organized by Projekt DEAL. The present work is supported by funding from the Deutsche Forschungsgemeinschaft (DFG, Project: GU 2102/2-1).

Data Availability The data used in this study are available from the corresponding author at reasonable request.

\section{Declarations}

Conflict of interest The authors declare that they have no conflict of interest.

Open Access This article is licensed under a Creative Commons Attribution 4.0 International License, which permits use, sharing, adaptation, distribution and reproduction in any medium or format, as long as you give appropriate credit to the original author(s) and the source, provide a link to the Creative Commons licence, and indicate if changes were made. The images or other third party material in this article are included in the article's Creative Commons licence, unless indicated otherwise in a credit line to the material. If material is not included in the article's Creative Commons licence and your intended use is not permitted by statutory regulation or exceeds the permitted use, you will need to obtain permission directly from the copyright holder. To view a copy of this licence, visit http://creativecommons.org/licenses/by/4.0/.

\section{References}

1. Holmberg, K., Erdemir, A.: Influence of tribology on global energy consumption, costs and emissions. Friction 5, 263-284 (2017). https://doi.org/10.1007/s40544-017-0183-5

2. Holmberg, K., Kivikytö-Reponen, P., Härkisaari, P., Valtonen, K., Erdemir, A.: Global energy consumption due to friction and wear in the mining industry. Tribol. Int. 115, 116-139 (2017). https:// doi.org/10.1016/j.triboint.2017.05.010

3. Zum Gahr, K.H., Doane, D.V.: Optimizing fracture toughness and abrasion resistance in white cast irons. Metall. Trans. A. 11, 613-620 (1980). https://doi.org/10.1007/BF02670698

4. Oliveira, C.G., Pinheiro, I.P.: Effect of niobium on the microstructure of high chromium white cast iron. In: MRS Advances, pp. 9-16. Springer, Berlin (2015)

5. Shchegolev, A.V., Ishkov, A.V., Ivanayskiy, V.V.: Comparative study of high-chromium cast iron coatings modified with WCW2C/Co+B4C+Ni/Al complexes and Cr3C2/PG-US25 ceramet. In: Solid State Phenomena, pp. 818-826. Trans Tech Publications Ltd, Freienbach (2020)

6. Tabrett, C.P., Sare, I.R., Ghomashchi, M.R.: Microstructure-property relationships in high chromium white iron alloys. Int. Mater. Rev. 41, 59-82 (1996). https://doi.org/10.1179/095066096790326 075

7. Maratray, F.: Choice of appropriate compositions for chromiummolybdenum white irons. AFS Trans. 79, 121-124 (1971)

8. Llewellyn, R.J., Yick, S.K., Dolman, K.F.: Scouring erosion resistance of metallic materials used in slurry pump service. Wear 256, 592-599 (2004). https://doi.org/10.1016/j.wear.2003.10.002

9. Karantzalis, E., Lekatou, A., Mavros, H.: Microstructure and properties of high chromium cast irons: effect of heat treatments and alloying additions. Int. J. Cast Met. Res. 22, 448-456 (2009). https://doi.org/10.1179/174313309X436637

10. Maratray, F., Usseglio-Nanot, R.: Factors affecting the structure of chromium and chromium-molybdenum white irons. Climax Molybdenum, Paris (1971)

11. Asensio, J., Pero-Sanz, J.A., Verdeja, J.I.: Microstructure selection criteria for cast irons with more than $10 \mathrm{wt}$ \% chromium for wear applications. Mater. Charact. 49, 83-93 (2002). https://doi.org/10. 1016/S1044-5803(02)00260-7

12. Wiengmoon, A., Pearce, J.T.H., Chairuangsri, T.: Relationship between microstructure, hardness and corrosion resistance in 20 wt. $\% \mathrm{Cr}, 27 \mathrm{wt} . \% \mathrm{Cr}$ and $36 \mathrm{wt} . \% \mathrm{Cr}$ high chromium cast irons. Mater. Chem. Phys. 125, 739-748 (2011). https://doi.org/10. 1016/j.matchemphys.2010.09.064 
13. Mercado, V.H., Mejía, I., Bedolla-Jacuinde, A.: Effect of load and sliding rate on the wear behavior of Ti-containing TWIP steel. J. Mater. Eng. Perform. 26, 2213-2225 (2017). https://doi.org/10. 1007/s11665-017-2635-5

14. Todaka, T., Shimizu, K., Kusumoto, K., Purba, R.H., Gaqi, Y.: Effect of carbon content on three-body abrasive wear characteristics of 28Cr-3Ni cast alloys. ISIJ Int. 61, 2274-2283 (2021). https://doi.org/10.2355/isijinternational.isijint-2021-099

15. Ruff, A.W.: Deformation studies at sliding wear tracks in iron. Wear 40, 59-74 (1976). https://doi.org/10.1016/0043-1648(76) 90018-1

16. Grützmacher, P.G., Rammacher, S., Rathmann, D., Motz, C., Mücklich, F., Suarez, S.: Interplay between microstructural evolution and tribo-chemistry during dry sliding of metals. Friction 7, 637-650 (2019). https://doi.org/10.1007/s40544-019-0259-5

17. Volkert, C.A., Minor, A.M.: Focused ion beam microscopy and micromachining. MRS Bull. 32, 389-399 (2007). https://doi.org/ 10.1557/MRS2007.62

18. Brenner, A.: Electrodeposition of Alloys: Principles and Practice. Academic Press, Cambridge (1963)

19. Shreir, L.L., Jarman, R.A., Burstein, G.T.: Corrosion Vol. 2: Corrosion Control. Butterworth-Heinemann, Oxford (1994)

20. Awang, M., Khalili, A.A., Pedapati, S.R.: A review: thin protective coating for wear protection in high-temperature application. Metals (Basel) 10, 42 (2020). https://doi.org/10.3390/met10 010042

21. Parangusan, H., Bhadra, J., Al-Thani, N.: A review of passivity breakdown on metal surfaces: influence of chloride- and sulfideion concentrations, temperature, and $\mathrm{pH}$. Emergent Mater. (2021). https://doi.org/10.1007/s42247-021-00194-6

22. Oriňáková, R., Turoňová, A., Kladeková, D., Gálová, M., Smith, R.M.: Recent developments in the electrodeposition of nickel and some nickel-based alloys. J. Appl. Electrochem. 36, 957-972 (2006)

23. Palumbo, G.: Smart coatings for corrosion protection by adopting microcapsules. Phys. Sci. Rev. 1, 1-32 (2019). https://doi.org/10. 1515/psr-2015-0006

24. ASM International: ASM Handbook Volume 5: Surface Engineering. ASM International, Novelty (2002)

25. Fontana, M.G.: Corrosion Engineering. McGraw-Hill, Singapore (1987)

26. Reid, J.: Copper electrodeposition: principles and recent progress. Jpn. J. Appl. Phys. 40, 2650 (2001). https://doi.org/10.1143/JJAP. 40.2650

27. Medlin, D.J., Lucas, G.M., Vander Voort, G.F.: Metallographic preparation of orthopedic medical devices. Med. Device Mater. II-Proc. Mater. Process. Med. Devices Conf. 2004. 75-80 (2005)

28. Nayak, U.P., Guitar, M.A., Mücklich, F.: A comparative study on the influence of chromium on the phase fraction and elemental distribution in as-cast high chromium cast irons: simulation vs. experimentation. Metals (Basel) 10, 30 (2020). https://doi.org/10. 3390/met10010030

29. Nayak, U.P., Suárez, S., Pesnel, V., Mücklich, F., Guitar, M.A.: Load dependent microstructural evolution in an As-cast 26\% Cr high chromium cast iron during unlubricated sliding. Friction (2021). https://doi.org/10.1007/s40544-021-0553-x

30. Nayak, U.P., Guitar, M.A., Mücklich, F.: Evaluation of etching process parameter optimization in the objective specific microstructural characterization of as-cast and heat treated HCCI alloy. Prakt. Metallogr. 57, 688-713 (2020). https://doi.org/10.3139/ 147.110682

31. Sato, N.: Basics of corrosion chemistry. In: Green Corrosion Chemistry and Engineering: Opportunities and Challenges, pp. 1-32. Wiley, Hoboken (2011)

32. Lin, C.S., Hsu, P.C., Chang, L., Chen, C.H.: Properties and microstructure of nickel electrodeposited from a sulfamate bath containing ammonium ions. J. Appl. Electrochem. 31, 925-933 (2001). https://doi.org/10.1023/A:1017970417874

33. Vander Voort, G.F.: Metallography: Principles and Practice. ASM International, Novelty (1999)

34. Hann, S.K., Gates, J.D.: A transformation toughening white cast iron. J. Mater. Sci. 32, 1249-1259 (1997). https://doi.org/10. 1023/A:1018544204267

35. Dodd, J.: Recent developments in abrasion resistant high chromium-molybdenum irons, low-alloy manganese steels and alloyed nodular irons of importance in the extraction and utilization of energy resources. J. Mater. Energy Syst. 2, 65-76 (1980). https:// doi.org/10.1007/BF02833432

36. Zumelzu, E., Goyos, I., Cabezas, C., Opitz, O., Parada, A.: Wear and corrosion behaviour of high-chromium (14-30\% Cr) cast iron alloys. J. Mater. Process. Technol. 128, 250-255 (2002). https:// doi.org/10.1016/S0924-0136(02)00458-2

37. Ivshin, Y.V., Shaikhutdinova, F.N., Sysoev, V.A.: Electrodeposition of copper on mild steel: peculiarities of the process. Surf. Eng. Appl. Electrochem. 54, 452-458 (2018). https://doi.org/10. 3103/S1068375518050046

38. Dini, J.W.: Electrodeposition: The Materials Science of Coatings and Substrates (Materials Science and Process Technology Series). William Andrew (1994)

39. Gabe, D.R.: The role of hydrogen in metal electrodeposition processes. J. Appl. Electrochem. 27, 908-915 (1997). https://doi.org/ 10.1023/A:1018497401365

40. Gómez, E., Pollina, R., Vallés, E.: Nickel electrodeposition on different metallic substrates. J. Electroanal. Chem. 386, 45-56 (1995). https://doi.org/10.1016/0022-0728(95)03817-Z

41. Schoeman, L., Sole, K.C.: Accurate measurement of polarization potentials during electrodeposition of nickel metal from sulphate electrolytes. J. S. Afr. Inst. Min. Metall. 117, 622-628 (2017). https://doi.org/10.17159/2411-9717/2017/V117N7A3

42. Holm, M., O'Keefe, T.J.: Evaluation of nickel deposition by electrochemical impedance spectroscopy. J. Appl. Electrochem. 30, 1125-1132 (2000). https://doi.org/10.1023/A:1004002303181

43. Böhni, H.: Breakdown of passivity and localized corrosion processes. Langmuir 3, 924-930 (1987). https://doi.org/10.1021/ la00078a010

44. Cheng, Y.F., Wilmott, M., Luo, J.L.: Role of chloride ions in pitting of carbon steel studied by the statistical analysis of electrochemical noise. Appl. Surf. Sci. 152, 161-168 (1999). https://doi. org/10.1016/S0169-4332(99)00328-1

45. Zhang, B., Wang, J., Wu, B., Guo, X.W., Wang, Y.J., Chen, D., Zhang, Y.C., Du, K., Oguzie, E.E., Ma, X.L.: Unmasking chloride attack on the passive film of metals. Nat. Commun. 9, 1-9 (2018). https://doi.org/10.1038/s41467-018-04942-x

46. Elfström, B.O.: The effect of chloride ions on passive layers on stainless steels. Mater. Sci. Eng. 42, 173-180 (1980). https://doi. org/10.1016/0025-5416(80)90026-9

47. Horvath, J., Uhlig, H.H.: Critical potentials for pitting corrosion of $\mathrm{Ni}, \mathrm{Cr}-\mathrm{Ni}, \mathrm{Cr}-\mathrm{Fe}$, and Related Stainless Steels. J. Electrochem. Soc. 115, 791 (1968). https://doi.org/10.1149/1.2411433

48. Richardson, T., Cottis, B., Lindsay, R., Lyon, S., Scantlebury, D., Stott, H., Graham, M. (eds.): Shreir's Corrosion. Elsevier, Amsterdam (2010)

49. Giourntas, L., Brownlie, F., Hodgkiess, T., Galloway, A.M.: Influence of metallic matrix on erosion-corrosion behaviour of high chromium cast irons under slurry impingement conditions. Wear 477, 203834 (2021). https://doi.org/10.1016/J.WEAR.2021. 203834

50. Kapoor, A., Franklin, F.J.: Tribological layers and the wear of ductile materials. Wear 245, 204-215 (2000). https://doi.org/10. 1016/S0043-1648(00)00480-4 
51. Ghabchi, A.: Wear Resistant Carbide-based Thermal Sprayed Coatings: Process, Properties, Mechanical Degradation and Wear. Stony Brook University, Stony Brook (2011)

52. Menezes, P.L., Ingole, S.P., Nosonovsky, M., Kailas, S.V., Lovell, M.R.: Tribology for Scientists and Engineers: From Basics to Advanced Concepts. Springer, New York (2013)

53. Miyamoto, G., Shibata, A., Maki, T., Furuhara, T.: Precise measurement of strain accommodation in austenite matrix surrounding martensite in ferrous alloys by electron backscatter diffraction analysis. Acta Mater. 57, 1120-1131 (2009). https://doi.org/10. 1016/j.actamat.2008.10.050
54. Abbaschian, R., Abbaschian, L., Reed-Hill, R.E.: Physical Metallurgy Principles. Cengage Learning, Stamford (2008)

55. Hull, D., Bacon, D.J.: Introduction to Dislocations. Elsevier Ltd, Oxford (2011)

Publisher's Note Springer Nature remains neutral with regard to jurisdictional claims in published maps and institutional affiliations. 